\title{
Graded compression for preventing deep venous thrombosis
}

\author{
C P HOLFORD
}

British Medical fournal, 1976, 2, 969-970

\section{Summary}

The physiological effects of static compression of the leg have recently been reinvestigated. Graded compression extending from the ankle to the upper thigh produces the maximum increase in velocity of femoral vein blood flow and the maximum decrease in clearance times of contrast media and radioisotopes from the deep veins of the calf. This type of compression may be easily produced by a specially designed elastic stocking.

Graded compression was used in a controlled clinical trial of 98 patients undergoing major operations to assess its effect on isotopically diagnosed deep vein thrombosis. The incidence of deep vein thrombosis was $\mathbf{4 9} \%$ in the control group and $23 \%$ in the treated group. No complications were caused by the stockings. Carefully designed and correctly applied static compression is a safe and effective method of reducing the incidence of deep vein thrombosis.

\section{Introduction}

Static compression may be defined as the application of a constant compressive force. Compressive forces may be applied to a limb so that they differ at various sites on the limb although the forces at the various sites remain constant. If constant compressive forces are applied to the limb so as to produce high levels of compression at some sites and lower ones at others the compression is termed graduated or graded compression.

Static compression has not been widely used in Great Britain for preventing deep vein thrombosis although it is safe, easily applied, and cheap. It would be acceptable to both patient and surgeon if it were known to be effective, but previous work in England has been inconclusive. ${ }^{1-3}$ There is now good evidence that correctly applied static compression increases venous flow velocity by an average of $38^{\circ}{ }_{0},{ }^{5}$ and reduces clearance times of radioisotopes and contrast media from the deep veins of the calf. ${ }^{6}$ It has become clear that the degree of compression applied is of critical importance if the maximum increase in velocity of venous flow is to be obtained. Sigel ${ }^{5}$ found that a graded compression of $18 \mathrm{~mm} \mathrm{Hg}$ at the ankle reducing to 8 $\mathrm{mm} \mathrm{Hg}$ over the thigh had the greatest effect. This type of graded compression was produced by a specially designed full length elastic stocking (Kendall Company).

Because of the improvements in the design of static compressive devices it was decided to investigate the effect of graded compression on the incidence of deep vein thrombosis in patients undergoing major surgery.

\section{Patients and methods}

Patients over 40 years of age who were about to undergo elective major surgery were entered into a controlled clinical trial. Major surgery was defined as a major abdominal, pelvic, or thoracic operation

Department of Surgery, Charing Cross Hospital, London W6 8RF C P HOLFORD, FRCS, senior surgical registrar -for example, cholecystectomy, abdominoperineal excision of the rectum, thoracotomy. Patients were allocated randomly to a stocking group or a control group by instructions in sealed envelopes. Stockings were available in nine different sizes, which enabled all patients in the trial to be correctly fitted. The stockings were fitted by a nurse or doctor 12 hours before operation and were not removed until the patient was fully ambulant, usually on the fourth or fifth day after operation.

No other specific method for preventing deep vein thrombosis was used, but all patients underwent the usual ward routine of encouraging early leg activity while in bed and early ambulation whenever possible.

${ }^{125}$ I-Fibrinogen scanning-Deep vein thrombosis was diagnosed by the ${ }^{125} \mathrm{I}$-fibrinogen test, the fibrinogen being obtained from the Radiochemical Centre, Amersham. Each patient received $100 \mu \mathrm{Ci}$ of ${ }^{125}$ I-fibrinogen on the day before surgery, after the thyroid gland had been blocked by either an oral or intravenous dose of $100 \mathrm{mg}$ sodium iodide. Scanning was performed with a Pitman 235 Localisation Monitor, using the technique of Kakkar $e t a l^{7}$ on the day before surgery and thereafter every day for at least six days. Venous thrombosis was diagnosed when counts rose by $20 \%$ or more at adjacent positions on the same limb or between similar positions on the two limbs, provided the rise was maintained for at least 24 hours.

\section{Results}

Ninety-eight patients entered the trial, but three were withdrawn, two in the stocking group and one in the control group, because of incomplete ${ }^{125} \mathrm{I}$-fibrinogen scanning. Of the 95 remaining patients 48 wore the stockings 47 were controls.

Deep vein thrombosis-Because many factors influence the incidence of deep vein thrombosis, especially age, duration of surgery, the presence of malignant disease, and the site of operation, the incidence of these variables is important (table I). All the patients underwent major operations, but five in the stocking group and four in the control group underwent thoracic procedures. The remaining patients had abdominal or combined abdominal and pelvic procedures. The matching of the two groups for these variables was good. Deep vein thrombosis developed in 34 of the 95 patients. It occurred in 23 control patients $(49 \%)$ and in 11 in the stocking group $(23 \%)$. This difference between the groups was statistically significant using a $\chi^{2}$ test with Yates's correction for small numbers $(0.025>P>0.01)$. Three controls developed deep vein thrombosis which propagated from the calf into the thigh, whereas this was seen in only one patient in the stocking group. Pulmonary embolism, confirmed by lung scanning, occurred in one patient in the control group. There were no pulmonary emboli clinically in the stocking group (table II). No patient died during the trial.

TABLE I-Variables affecting frequency of deep vein thrombosis in patients undergoing major surgery

\begin{tabular}{l|c|c|c|c}
\hline Group & $\begin{array}{c}\text { No of } \\
\text { patients }\end{array}$ & $\begin{array}{c}\text { Mean age } \\
( \pm 1 \text { SD) } \\
\text { (years) }\end{array}$ & $\begin{array}{c}\text { No (\%) with } \\
\text { malignancy }\end{array}$ & $\begin{array}{c}\text { Mean duration } \\
\text { of surgery } \\
( \pm 1 \text { SD) } \\
\text { (minutes) }\end{array}$ \\
\hline $\begin{array}{l}\text { Control } \\
\text { Stocking }\end{array}$ & 47 & $\begin{array}{l}59 \pm 9 \cdot 5 \\
58 \pm 10 \cdot 7\end{array}$ & $9(19)$ & $106 \pm 50 \cdot 0$ \\
\hline
\end{tabular}

TABLE II-Propagation into thigh, site of deep vein thrombosis (DVT), and pulmonary embolism

\begin{tabular}{l|c|c|c|c}
\hline Group & $\begin{array}{c}\text { No with } \\
\text { propagation } \\
\text { into thigh }\end{array}$ & $\begin{array}{c}\text { No (\%) with } \\
\text { bilateral } \\
\text { DVT }\end{array}$ & $\begin{array}{c}\text { No with } \\
\text { single leg } \\
\text { DVT }\end{array}$ & $\begin{array}{c}\text { No with } \\
\text { pulmonary } \\
\text { embolus }\end{array}$ \\
\hline $\begin{array}{c}\text { Control }(\mathrm{n}=23) \\
\text { Stocking }(\mathrm{n}=11)\end{array}$ & $\mathbf{3}$ & $\mathbf{9}(29)$ & $\mathbf{1 4}$ & $\mathbf{8}$ \\
\hline
\end{tabular}


Malignancy in patients with deep vein thrombosis-Of the 11 patients in the stocking group who developed deep vein thrombosis four had malignant disease (36\%), compared with six (27\%) of the 23 controls with deep vein thrombosis. Three patients who wore stockings $(27 \%)$ and nine controls $(39 \%)$ developed bilateral deep vein thrombosis (table II).

\section{Discussion}

Earlier trials of static compression for preventing deep vein thrombosis have been equivocal but the consensus of opinion has been that it is ineffective. In most trials, however, the compressive device has been badly designed. Usually elastic bandages or cylinders of elastic material-for example, Tubigrip -have been used. ${ }^{3}$ The compressive force applied to the leg by these methods varies greatly. In theory elastic bandages could be applied to take full account of the size and shape of the leg, but in practice their application cannot be standardised. The cylinders of elastic material are especially inappropriate as the lower limb is not cylindrical in shape but is more like an inverted cone. If cylindrical compression is applied to a cone-shaped structure the compressive force will be greatest at the cone's largest circumference-namely, the calf and thigh. The effect on the leg is much the same as that of applying a tourniquet at these sites.

Using graded compression, which takes account of the leg's conical shape and may be easily obtained by an appropriately designed elastic stocking, it is possible to reduce the incidence of deep vein thrombosis in patients undergoing major surgery from $49 \%$ to $23 \%$. The incidence in the control group was high, but this was accounted for by including only those patients undergoing major operations. There were too few patients to say whether static compression affected propagation of thrombus into the thigh or the incidence of pulmonary embolism. But
Wilkins ${ }^{8}$ reported in 1952 that static compression reduced the incidence of fatal pulmonary embolism fourfold. The higher incidence of malignant disease among the patients wearing stockings who developed deep vein thrombosis suggests that static compression may not be as effective in those with malignancy.

Despite possible defects in certain areas of deep vein thrombosis prevention with this method, a worthwhile reduction was observed. The stockings are easy to fit and need no maintenance after they are fitted. The stockings caused no complications and there were no complaints from patients or surgeons, largely because of the advance in design of compressive devices in recent years. Further investigation of the physiological and clinical effects of these devices is needed. Clinically this would best be met by a large scale trial reassessing their effect on pulmonary embolism.

I thank Professor A J Harding Rains, Mr B P Bliss, Mr A G Johnson, $\mathrm{Mr} \mathrm{J} \mathrm{E} \mathrm{H} \mathrm{Pendower,} \mathrm{and} \mathrm{Mr} \mathrm{K} \mathrm{W} \mathrm{Reynolds} \mathrm{for} \mathrm{permission} \mathrm{to}$ study patients under their care; the nursing staff for their co-operation; Mrs S Jennings for technical help; and the Kendall Company, Barrington, Illinois, for providing the stockings.

Requests for reprints should be addressed to $\mathrm{Mr} \mathrm{C}$ P Holford, Department of Surgery, Charing Cross Hospital, London W6.

\section{References}

1 Tsapogas, M J, et al, Archives of Surgery, 1970, 101, 149.

2 Rosengarten, D S, et al, British fournal of Surgery, 1970, 57, 296.

${ }^{3}$ Browse, N L, et al, British fournal of Surgery, 1974, 61, 219.

4 Sigel, B, et al, Archives of Surgery, 1973, 106, 38.

5 Sigel, B, et al, Archives of Surgery, 1975, 110, 171.

${ }^{6}$ Lewis, F C, et al, Southwestern Surgical Congress, 3-6 May, 1976.

7 Kakkar, V V, et al, Lancet, 1970, 1, 540.

${ }^{8}$ Wilkins, R W, et al, New England fournal of Medicine, 1952, 246, 360.

\title{
Changes in nystagmus on raising body temperature in clinically suspected and proved multiple sclerosis
}

\author{
J V JESTICO, P D M ELLIS
}

British Medical fournal, 1976, 2, 970-972

\section{Summary}

Electronystagmography was used to record the appearance or alteration of nystagmus after raising the body temperature by a heat cradle. Nystagmus was increased or provoked in 13 out of 15 patients with clinically proved multiple sclerosis, in eight out of 12 suspected cases, but in no normal controls. No positive results were obtained in 12 patients with other neurological diseases, even when nystagmus was part of the clinical picture. The technique is simple to use and may have a role in the diagnosis of multiple sclerosis.

\footnotetext{
National Hospital for Nervous Diseases, Queen Square, London WC1N 3BG

J V JESTICO, BSC, MRCP, research registrar

Ferens Institute of Otolaryngology, Middlesex Hospital, London W1N 8AA

P D M ELLIS, FRCS, senior registrar
}

\section{Introduction}

An increase in body temperature in multiple sclerosis often causes a transient deterioration in the clinical state. ${ }^{1}$ This may be accompanied by an exacerbation of existing neurological signs and, in some cases, the appearance of new physical signs, which resolve as the temperature returns to normal. ${ }^{2-4}$ Up to now the somewhat inconvenient "hot-bath" test has been widely used in diagnosis in cases of suspected multiple sclerosis. We have developed a simple quantitative technique for studying the appearance or alteration of nystagmus induced by changes in body temperature and are at present assessing its value in the clinical diagnosis of multiple sclerosis. We report here our preliminary results in cases of clinically proved and suspected multiple sclerosis as well as in some other neurological disorders.

\section{Patients and method}

Thirty-nine patients and 10 normal controls were studied. Of the patients, 15 had clinically definite multiple sclerosis, 12 suspected multiple sclerosis, and 12 other neurological diseases. The controls comprised a man and a woman in each of the third, fourth, fifth, sixth, and seventh decades of life. 